\title{
REVISIÓN DE USOS SOCIALES Y FORMAS DE EJERCER LA POLITICA A TRAVES DE LOS NUEVOS MEDIOS
}

\author{
Review of social practices and ways of exercising the \\ policy through new media
}

\section{Ildefonso Cordero-Sánchez y Jordi Alberich-Pascual}

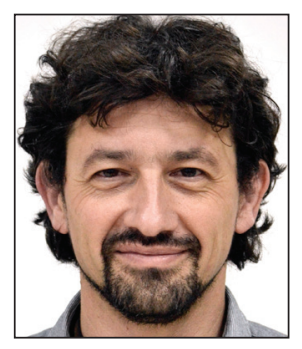

Ildefonso Cordero-Sánchez es licenciado en comunicación audiovisual y en derecho por la Universidad de Granada. Estudiante de doctorado en el Departamento de Comunicación e Información de la Facultad de Comunicación y Documentación de la Universidad de Granada es premio extraordinario de fin de carrera de la licenciatura de comunicación audiovisual (2011) y accesit nacional fin de carrera del Ministerio de Educación (BOE 112, de 8 de mayo de 2014). http://orcid.org/0000-0002-4559-2228

inchocordero@gmail.com

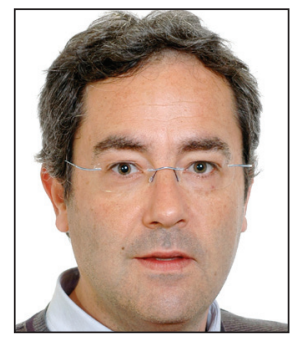

Jordi Alberich-Pascual, doctor por la Universidad de Barcelona (1998), es profesor titular de universidad de comunicación audiovisual y publicidad en la Facultad de Comunicación y Documentación de la Universidad de Granada. Ha desempeñado su actividad investigadora como experto en estética y cultura audiovisual digital. Es miembro del laboratorio de investigación Secaba, e investigador colaborador del grupo de investigación SCI2S (Soft Computing and Intelligent Information Systems) y del Internet Interdisciplinary Institute IN3, centro de investigación de excelencia de la Universitat Oberta de Catalunya.

http://orcid.org/0000-0001-6871-4614

jalberich@ugr.es

Universidad de Granada, Facultad de Comunicación y Documentación, Departamento de Información y Comunicación Campus Cartuja, s/n. 18071 Granada, España

\section{Resumen}

Se realiza una revisión de los elementos que han facilitado mayor autonomía comunicativa a significativos movimientos y organizaciones sociales contemporáneas a través de los nuevos medios. Tomando como referencia inicial el diagnóstico histórico de Hans Magnus Enzensberger (1970) para un uso emancipador de los medios de comunicación social, ofrecemos a continuación el proceso de emergencia y desarrollo de un nuevo paradigma informacional afín en la actividad de representativos movimientos sociales contemporáneos a escala global. Finalmente ofrecemos un catálogo de elementos comunes puestos en práctica por estos movimientos para la promoción de la gestión abierta y emancipadora de los nuevos medios como herramienta de empoderamiento social.

\section{Palabras clave}

Nuevos medios; Empoderamiento informacional; Autocomunicación; Emancipación social; Cultura libre; Libertad de expresión; Independencia informativa; Prensa independiente.

\begin{abstract}
This article reviews the elements that have facilitated greater communicative autonomy for significant contemporary social movements and organizations through new media. Taking as reference the historical diagnosis of Hans Magnus Enzensberger (1970) for an emancipatory use of social media, we analyse the process of emergence and development of a new information paradigm in the global activity of contemporary social movements. Finally, we offer a selection of common elements implemented by these movements for the promotion of open and emancipatory management of new media as a tool for social empowerment.
\end{abstract}

\section{Keywords}

New media; Informational empowerment; Self-communication; Social emancipation; Free culture; Freedom of expression; Editorial independence; Independent press. 
Cordero-Sánchez, Ildefonso; Alberich-Pascual, Jordi (2015). "Revisión de usos sociales y formas de ejercer la política a través de los nuevos medios". El profesional de la información, v. 24, n. 6, pp. 811-818.

http://dx.doi.org/10.3145/epi.2015.nov.13

\section{Introducción}

La autogestión de la información y comunicación ha constituido un factor clave en el empoderamiento de los agentes sociales desde finales del siglo XX (Katz; Rice, 2002; Cardoso, 2008; Castells, 2009). El presente artículo persigue explorar las condiciones estratégicas que debieran implementarse en los nuevos medios de comunicación digital para su plena apertura y accesibilidad social en la sociedad de la información, desterrando las inercias limitadoras cuando no represoras propias de modelos mediáticos previos, de acuerdo con el análisis de Hans-Magnus Enzensberger (1970).

Frente al carácter cerrado, estable y mayoritariamente limitado de la creación y difusión en los medios tradicionales, la acción comunicativa a través de los denominados nuevos medios posibilita modelos innovadores de producción cultural abiertos y participativos, alternativos al modelo precedente, jerárquico y cerrado (Thorburn; Jenkins, 2004; Jenkins, 2008).

La acción comunicativa a través de los denominados nuevos medios posibilita modelos innovadores de creación y producción cultural abiertos y participativos

Para ello se realiza la prospección de aquellos elementos comunes que desde finales del siglo XX hasta la actualidad han facilitado una mayor autonomía comunicativa a significativos movimientos sociales contemporáneos. Se persigue contribuir a una teoría de los nuevos medios en afinidad con un nuevo y emergente paradigma emancipador de los medios de comunicación social, como han evidenciado estudios recientes de Baillie-Smith (2004; 2013), Nos, Iranzo y Farné (2012), Nos y Pinazo (2013), o Lünenborg y Raetzsch (2014) entre otros.

Son igualmente cruciales para la acotación del marco teórico, por una parte las aportaciones sobre conceptualización y promoción de una cultura participativa emergente en pos del conocimiento abierto y del dominio público en la sociedad de la información, de autores como Himanen (2001), Stallman (2002) o Lessig $(2004,2008)$ a nivel internacional. Y por otra parte, los trabajos en el panorama nacional de Casacuberta (2003) en relación con la proactividad del público digital, o de Sampedro (2014) en pos de un periodismo de código libre.

Aun cuando esta investigación es fundamentalmente cualitativa, se centra en una selección de plataformas de comunicación alternativa surgidas tras la Cumbre de la OMC de Seattle en 1999, premiando a su vez la selección de los elementos en los que nuevos medios y redes sociales han tenido un papel determinante para el éxito y/o eco de ini- ciativas de empoderamiento informacional para el cambio social. Utilizamos una metodología multidisciplinar en la medida que nuestro objeto de estudio necesita apoyarse en estudios de comunicación, sociología y ciencias políticas de forma transversal.

\section{Hacia un uso emancipador de los medios de comunicación social}

En Baukasten zu einer Theorie der Medien (1970), HansMagnus Enzensberger planteaba las repercusiones sociales y políticas de los medios de comunicación a partir del estudio del control y de la ideología de los contenidos difundidos por éstos. En esta pequeña obra de amplio eco posterior en el debate sobre el fin y la naturaleza de los medios de comunicación en las sociedades modernas, su autor concluía que éstos pueden ser un instrumento de represión y de mantenimiento del statu quo existente. Sin embargo, reflexionaba al mismo tiempo sobre su posibilidad para articularse como instrumentos efectivos de emancipación y liberación, y detallaba este posible doble uso de los medios de comunicación represivo/emancipador a partir de un catálogo de elementos cualitativamente distintivos entre ambos usos.

De acuerdo con Enzensberger, el uso represivo de los medios se fundamenta en la centralización del control de los medios, la existencia de un transmisor para muchos receptores, y en que no todo el mundo tenga el mismo acceso a ellos.

Propician la inmovilización de individuos aislados, así como una conducta de consumo inconsciente y compulsivo, motor del sistema capitalista. Favorecen un proceso de despolitización y aletargamiento del espíritu crítico y político de los ciudadanos, y en ellos se limita el acceso a la creación y a la producción de programas y contenidos a especialistas, manteniéndose asimismo su control en todo momento en manos de propietarios o burócratas.

Por el contrario, un (potencial) uso emancipador de los media debería considerar a cada receptor como un transmisor pleno en potencia, y capacitar programas y contenidos descentralizados: cuanta mayor pluralidad en los medios, más puntos de vista al alcance de los ciudadanos. Toda persona debe tener el poder potencial de convertirse en un productor de comunicación mediática. El uso emancipador de los medios debe capacitar la movilización de las masas, que los ciudadanos se auto organicen y se movilicen, y promover su interacción y feedback. La producción deberá ser colectiva y colaborativa, ya no sólo obra de especialistas, sino también de agentes sociales, y su control estará socializado a través de organizaciones autogestoras.

Este modelo prospectivo sobre un uso emancipador de los medios dialoga con las posibilidades que conllevan hoy internet y los nuevos medios de comunicación digital para el 
empoderamiento informacional y la emancipación social en la sociedad de la información, en la que:

- se facilita una mayor autonomía a los usuarios independientes;

- se rebajan las barreras de entrada a la creación, producción y difusión de obras, programas y contenidos;

- se proporciona una mayor capacidad de acceso, interacción y participación a los públicos (Tubella; Alberich-Pascual, 2012).

Los medios de comunicación tradicionales han perdido el monopolio de la información. Internet y la nueva cultura digital son testimonios de la expansión a campos abiertos y comunales de los procesos de producción, distribución, creación informativa y consumo cultural, antes tradicionalmente cerrados y restringidos a las dinámicas exclusivas de los medios tradicionales. Se trata de un nuevo entorno donde los medios no sólo coexisten, sino que se interrelacionan y se influyen mutuamente en múltiples dimensiones (Jenkins, 2004). La evolución interna de los usos sociales y culturales de internet ha acentuado la comunicación de muchos a muchos inherente a la red de redes; esto es, la apropiación, el uso común de internet y la conversión de los propios usuarios en emisores constantes y masivos, aquello que Dan Gillmor denominara We, the media (2006).

La constatación de este proceso abre un interesante debate sobre el alcance y la emergencia revolucionaria de los denominados nuevos medios, en relación con sus antecesores.

“En la década de 1990 se utilizó el término 'nuevos medios' como forma abreviada de nuevas formas culturales que dependen de los ordenadores digitales para su distribución (...) Pero más allá de su significado descriptivo, el término también llevaba consigo la promesa de una innovación cultural radical" (Manovich, 1999).

Esta innovación no es tanto tecnológica como de la utilización que se hace de estos medios por parte de los actores sociales para la independencia comunicativa y la emancipación social.

\section{Nuevo paradigma informacional en los movimientos sociales}

Las protestas contra la Cumbre de la OMC de Seattle en 1999 inauguran una nueva era informacional para los movimientos sociales. Jeffrey Juris cita este evento como el germen de una nueva forma de producir información basada en la velocidad, la adaptabilidad y la flexibilidad que otorgan las nuevas tecnologías de la información, que permiten hacer competencia a la formas más tradicionales de jerarquías verticales. Se marca, en palabras de Juris, una tendencia de los movimientos sociales a reflejar la amplia lógica descentralizada del informacionalismo, incluso cuando atacan las raíces del capitalismo informacional (Juris, 2008).

El cambio de paradigma se lleva a cabo en un doble plano:

A nivel interno, los nuevos modelos de acción comunicativa:

- ayudan a extender los lazos entre movimientos sociales de diferentes territorios y a conectar luchas y reivindicaciones;
- mejoran la coordinación de estrategias a nivel global;

- internacionalizan los objetivos políticos;

- permiten canalizar una respuesta organizada por parte de los agentes sociales.

La creación de plataformas y coordinadoras permite reproducir en el mundo físico el modelo de la nueva red informacional (Castells, 2006; Mazlish; Sanz; Arnáiz, 1995).

A nivel externo, da lugar a una concepción renovada de activismo mediático, mediante prácticas de contrainformación. Se crean espacios de información, análisis y profundización en relación con temas silenciados por los grandes medios, que chocan con los intereses de las grandes corporaciones. A la vez se hace una labor de reeducación del lector pasivo en un activista mediático, fomentando estructuras descentralizadas, organizadas mediante nodos y rompiendo con los modelos clásicos de jerarquías.

El modelo prospectivo sobre un uso emancipador de los medios de comunicación social dialoga con las opciones y posibilidades que conlleva hoy internet

El cambio de perspectiva que asumen los movimientos sociales con el nuevo siglo viene dado por concebir la información como un elemento insurgente y de ejercicio del poder: si la información no es fuente de poder, riqueza o significado no tiene valor en sí misma (Castells, 2006, p. 31). Por tanto la comunicación pasa de ser una consecuencia inevitable de la acción reivindicativa, como tradicionalmente se venía concibiendo, a constituirse en un arma estratégica en la reubicación sociopolítica de los movimientos sociales. Y sobre todo sirve para descubrir un mundo en el que hasta entonces los movimientos sociales se resistían a adentrarse.

Esta experiencia se refuerza en las respuestas que van articulando los movimientos por la justicia global en convocatorias sucesivas. Así por ejemplo, el People's Global Action $(P G A)$, recogiendo y vertebrando el recorrido de la lucha zapatista unos años antes, consigue que los movimientos por la justicia global se doten de tres características:

- ser globales, coordinados y comunicados a través de redes transnacionales;

- ser informacionales mediante una comunicación muy simbólica de la protesta militante;

- estar organizados en redes flexibles y descentralizadas, constituyendo una alternativa a la lógica organizativa dominante del capitalismo en la era de la información (Castells, 2006).

Este tipo de acciones alcanzará su perfeccionamiento en las contracumbres sociales en contestación a los foros mundiales de Davos, el G8, la OMC y otras corporaciones de carácter supranacional a partir del año $2000^{1}$.

Es extensa la literatura social que recoge las experiencias que nacen al amparo de estas redes organizacionales e informacionales, muchas de ellas originadas en manifiestos y 
Publicar en kaos ¿Quiénes somos? Contacto Webs amigas Dossier PP-Franquismo Poemario Anticonsumista Entra Registra

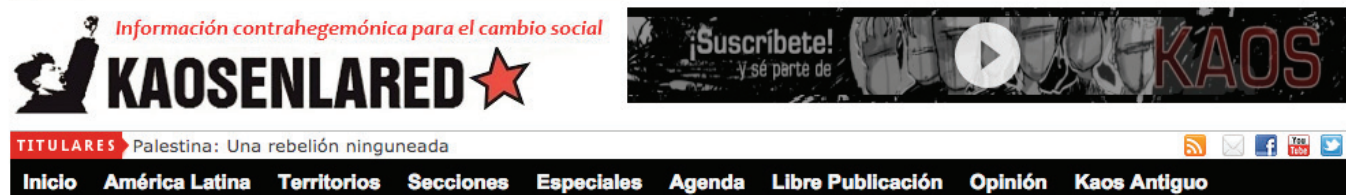
Inicio

\section{[\#4MesesSinAlfon] Elena Ortega: "Gracias al cariño que recibimos nos sostenemos en pié y comprometidos con la lucha por nuestros derechos y libertades"}

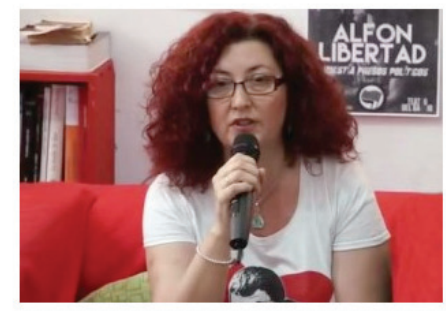

列 4 meses desde que Alfon fue llevado ese 17 de junio desde arroquia de San Carlos Borromeo, pero es evidente quela fuerta de sus compañeros, compañeras y familiares, no decae. Kaosenlared Leer mas

(El "paciente salvado" del PP) El número pobres y en riesgo de exclusión registra máximos históricos en el estado español 13.657.232 personas

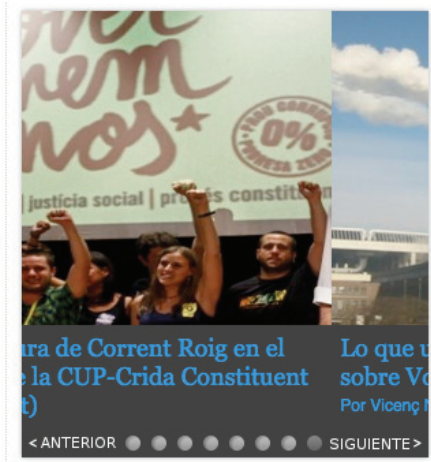

http://kaosenlared.net

declaraciones de intenciones de movimientos de protesta ciudadanos, centros sociales ocupados y redes informales. No obstante, el buque insignia durante años fue el conocido Centro de Medios Independientes, que bajo la marca Indymedia creó un potente sistema de comunicación alternativa basado en herramientas multimedia y estructuras no jerárquicas (Pickerill, 2007, p. 18).

https://www.indymedia.org/es

Su estructura de nodos, que muchas veces no tenían nada que ver con límites geográficos, políticos, sociales o culturales clásicos, introdujo un nuevo concepto de información social. De esta manera consiguió que grandes eventos que acababan siendo silenciados por los medios convencionales tuvieran repercusión mediática, a lo que contribuyó el auge de internet y la incipiente capacidad de los ciudadanos para decidir y reprogramar sus prioridades a nivel informativo. Pese a ello, su priorización de una estrategia de descentralización y autonomía local le dificultó crear estrategias proactivas y decisiones colectivas (Wolfson, 2013), e Indymedia perdió influencia en el mundo de la contrainformación con la aparición de las redes sociales, exhibiendo su debilidad para adaptarse a un mundo que cambiaba vertiginosamente.

Otras experiencias como las que abanderaron los colectivos Kaos en la Red, Altavoz por la Libertad de Expresión (nodo50.org) siguen vivas y fueron el origen de un nuevo escenario definido por López y Roig (2006) como el paso del narrowcasting al netcasting, un espacio donde el Estado puede apagar máquinas o desmontar redes, pero en el que es técnicamente imposible la regulación.

http://kaosenlared.net

http://info.nodo50.org

Valgan estas dos referencias de ejemplo, por ser pioneras en el mundo del activismo mediático nacido en las luchas de la resistencia global. Pero hay muchas más, que han ido marcando una evolución en las formas de construir infor- http://www.lamarea.com http://www.diagonalperiodico.net

La estrategia de apropiarse de los contenidos y establecer las prioridades en la comunicación por parte de los movimientos sociales ha ido acompañada de la idea inherente de apropiarse de la tecnología y de los medios necesarios (Candón, 2012, p. 83) para poder crear y difundir un mensaje que los grandes medios de comunicación escondían a los ciudadanos.

\section{El cambio de perspectiva que asumen los movimientos sociales en el nuevo si- glo viene dado por concebir la informa- ción como un elemento insurgente y de ejercicio del poder}

La tendencia dominante por parte de las redes de activismo social en los últimos quince años ha sido romper con la dependencia mediática que habían experimentado durante décadas los movimientos sociales, basada en la existencia de una red oligopólica (Candón, 2011, p. 218), muchas veces por falta de una política y un modelo de acción comunicativa definidas con la intención de generar mecanismos de transformación social. Este nuevo modelo ha exigido una emancipación de las tecnologías y medios necesarios para gozar de mayor independencia frente a los medios de masas a los que tradicionalmente recurrían buscando un canal de transmisión de ideas y valores.

El escenario tradicional de falta (y en ocasiones de rechazo) de recursos técnicos y de modelo de acción comunicativa dejaba en manos de los medios convencionales no sólo la creación del mensaje, sino su nivel de profundidad. De la misma manera los movimientos sociales han sufrido el desprecio histórico a cualquier acción reivindicativa por parte 
de los agentes responsables de la información, a los que siempre han criticado la vinculación entre los intereses corporativos y políticos y la gran superficialidad en la atención informativa que prestaban a sus causas (Berardi, 2007).

La apropiación de medios y discursos ha ido cambiando la fisonomía de las redes de comunicación de estas organizaciones de forma vertiginosa. Se ha creado un paradigma comunicativo descentralizado, horizontal y participativo, gracias a la búsqueda de una soberanía tecnológica que dotara de herramientas autosuficientes a los movimientos sociales. Esta soberanía tecnológica ha contribuido a la emancipación informativa mediante la creación de medios independientes por parte de la sociedad civil (Singer et al., 2011), y

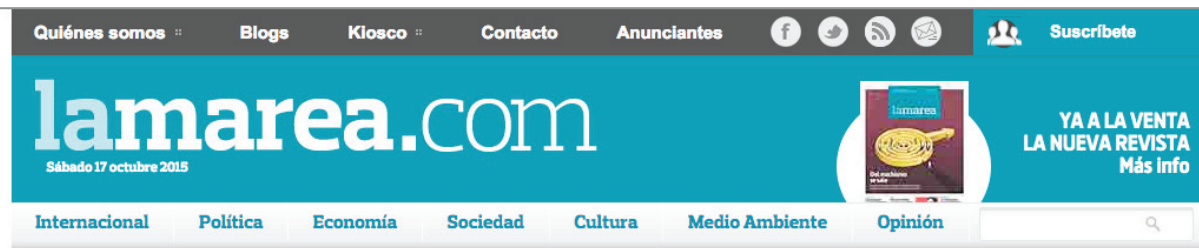

\section{Gaza: La violencia por la supervivencia}

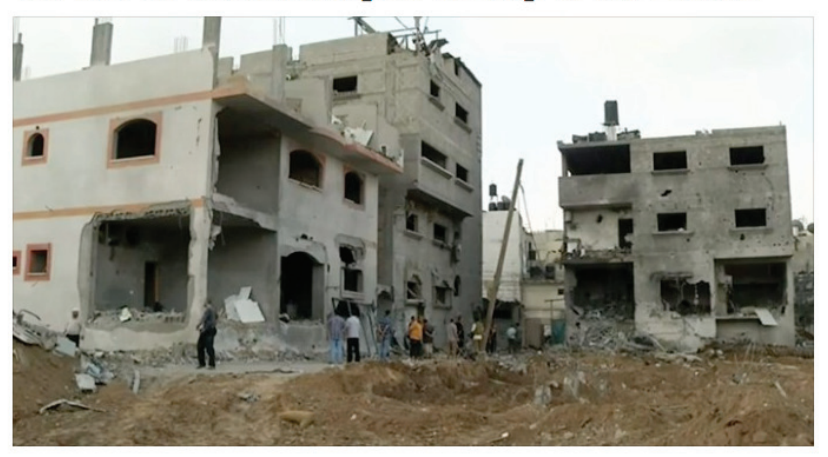

Barrio de la Franja de Gaza tras los bombardeos del pasado verano.

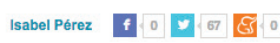

Desde que comenzó el mes de octubre, ocho israelies han muerto en ataques palestinos. Por su parte, las fuerzas israelies han acabado con la vida de 37 palestinos, 14 de ellos en la Franja de Gaza.

III La sombra de una nueva Intiffada aparece tras los ataques aéreos de Israel en Gaza Ii: La mortallidad infantil aumenta en Gaza por primera vez en 53 años III Un pesquero ante el ejército más moderno del mundo

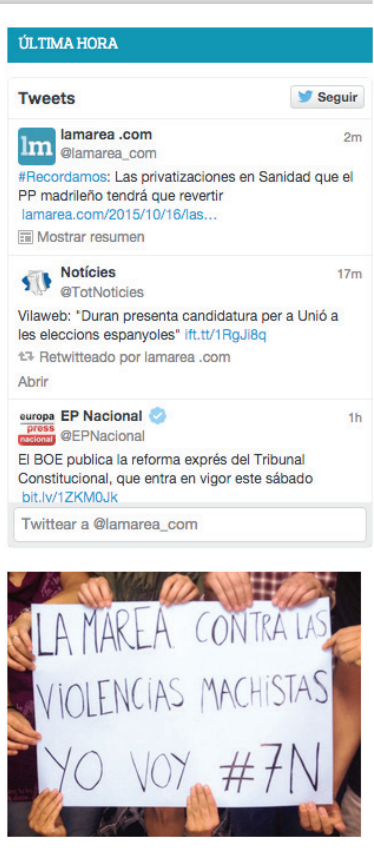

http://www.lamarea.com ha provocado una revisión estructural de las líneas de acción comunicativa de estos nuevos agentes sociales (Haché, 2015, p. 18).

La tendencia dominante por parte de las redes de activismo social en los últimos quince años ha sido romper con la dependencia mediática que habían experimentado durante décadas los movimientos sociales, basada en la existencia de una red oligopólica

Los movimientos sociales se han ido dotando además de técnicos especializados que han facilitado una cultura de la comunicación en muchas organizaciones activistas que en otro momento ni se planteaban comunicar su actividad. Estas iniciativas de soberanía tecnológica han fomentado, en palabras de Haché (2015, p. 18), la transformación social a través del empoderamiento de sus participantes. Entre éstos destacan los profesionales de la información, que al incorporar sus visiones profesionales a los movimientos sociales, han contribuido decisivamente a la creación de lo que se podría denominar activismo mediático, decisivo en el fortalecimiento de una comunicación independiente en la que visibilizar las realidades escondidas habitualmente por los grandes medios generalistas.

\section{En conclusión: elementos comunes para} la emancipación social y el empoderamiento comunicacional a través de los nuevos medios (1999-2014)

Los nuevos modelos de organización experimentados por los movimientos sociales a finales del siglo XX, crean el escenario idóneo para lo que Enzensberger (1970) llamó uso emancipador de los medios. El creciente uso de las nuevas tecnologías en un momento de internacionalización de la lucha social, fue entendido por los movimientos sociales como una excelente oportunidad para crear entornos de soberanía informativa, abriendo la puerta a un nuevo activismo mediático.

Esta emergencia y evolución desde 1999 de estructuras organizacionales y formas de trabajo tendentes a la emancipación social y al empoderamiento comunicacional por parte de los movimientos sociales, ha articulado una serie de elementos comunes en su uso y apropiación de los nuevos medios.

\subsection{Ejercer el derecho de autocomunicación}

Las formas de apropiación de los medios y de los discursos que vienen realizando agentes de la sociedad civil en la última década, tienen como fundamento común incorporar el derecho a la comunicación, o como denomina Castells (2009, p. 397), el derecho de autocomunicación (utilizando tanto las redes de comunicación horizontales como los medios mayoritarios para difundir mensajes e imágenes). Este derecho forma parte de sus luchas tanto para ser informados verazmente, como para ejercer de informadores. 


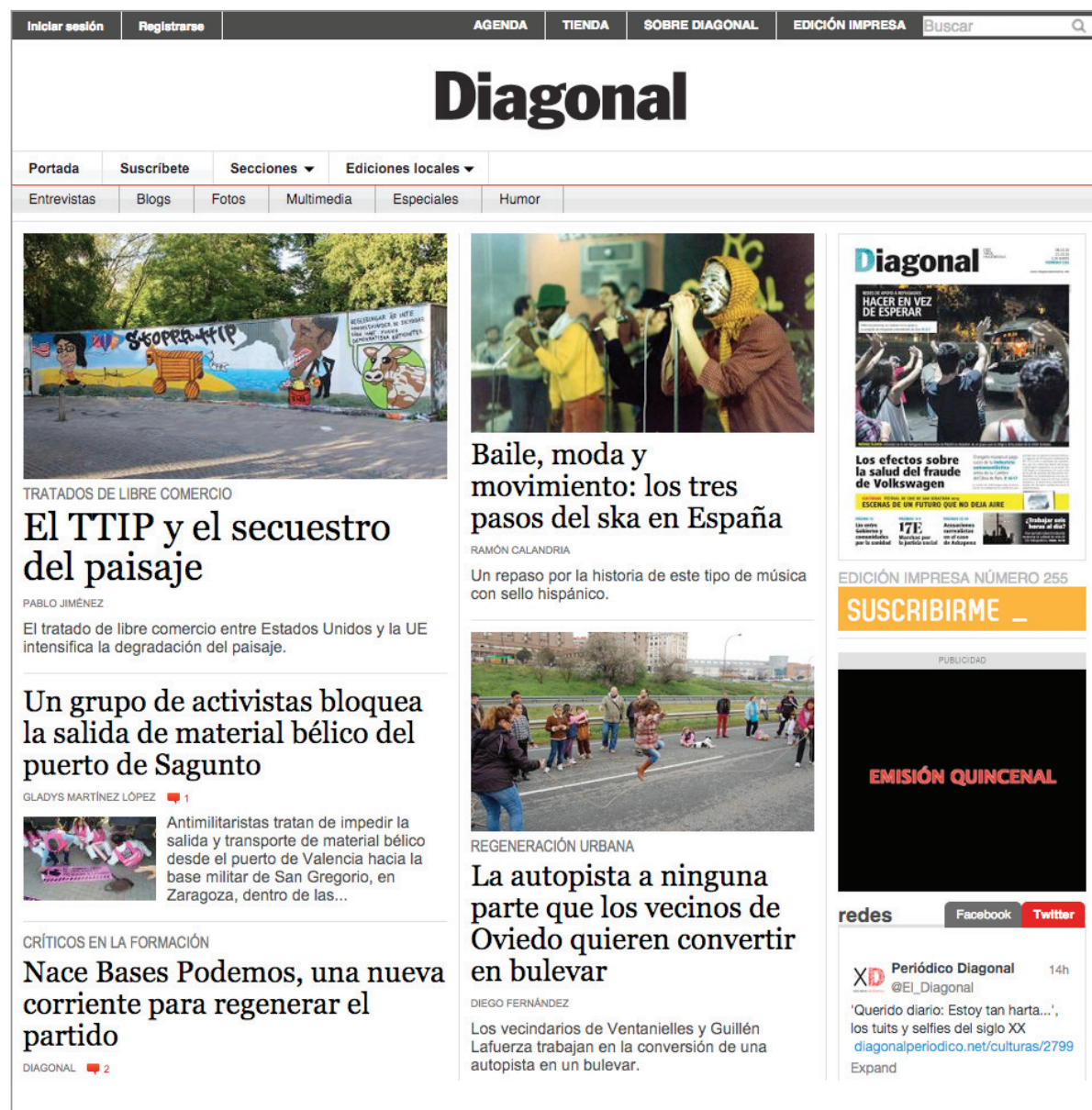

http://www.diagonalperiodico.net

Esta doble acepción había sido considerada como uno de esos derechos de tercera generación difícilmente realizables, con un reconocimiento más teórico que práctico, potenciado a su vez por el propio victimismo de los movimientos sociales situados en la izquierda del pensamiento político, reacios habitualmente a cualquier tipo de innovación por considerar que los medios respondían únicamente a su instinto comercial y a sus intereses corporativos (Berardi, 2007). La aparición de internet y de los nuevos medios promoverá en estos movimientos sociales un renovado esfuerzo común por ejercer este derecho de un modo efectivo.

\subsection{Desinterés por las prácticas comunicativas con- vencionales}

Los controles administrativos y regulación de los espacios radioeléctricos por parte de los gobiernos se ve relativizada a resultas de la irrupción e institucionalización de internet. La pretendida neutralidad de la Red rompe con un sistema monopolístico de facto, en el que los intereses corporativos habían lastrado históricamente las posibilidades de una comunicación libre y universal². Los nuevos movimientos sociales se desinteresan por la prácticas comunicativas convencionales de agentes sociales como partidos políticos y sindicatos (López; Roig; Sádaba, 2003). Frente a las pulsiones público-estatales de regulación y a las privadas-comerciales de sometimiento al mercado, llevan a cabo un modelo comunicativo en el que colaborar en su avance se convierte en un objetivo en sí mismo, no tan interesado en captar adhesiones o votos sino en crear sentido de pertenencia a las causas sociales. Un nuevo escenario que encuentra en internet "un ecosistema fértil para la política y se beneficia de la pérdida del privilegio en la acción política por parte de los partidos políticos" (Gutiérrez-Rubí, 2014, p. $51)$.

\subsection{Creación de redes de in- formación y comunicación transnacionales}

La apropiación de los medios de producción informativa, afín con el surgimiento del movimiento antiglobalización, se produce en gran medida mediante la vertebración de redes transnacionales de información y comunicación independiente ${ }^{3}$. Al amparo de estas redes surgen prácticas comunicativas que van más allá de la necesidad de visibilizar la acción política de organizaciones y movimientos sociales. Apoyadas en infraestructuras de carácter activista, como fueron los primeros proveedores de servicios de internet al margen de las grandes compañías, fomentan la importancia del sentido y propiedad colectiva de las acciones (Juris, 2008). Este fue el origen de iniciativas transnacionales como Indymedia, que supuso el germen de una apuesta común por un modelo de comunicación descentralizada y global en los movimientos sociales.

\subsection{Fundamentación tecnológica en una cultura de código abierto}

El nuevo activismo mediático evoluciona en los nuevos medios a partir de una cultura basada en la ética hacker (Himanen, 2001), en la que el fundamento de las fuentes y códigos abiertos rompen con una filosofía tradicional de funcionamiento, fuerzas organizativas y economía política de los medios, a la vez que trasciende la visión puramente comercial de los grandes conglomerados mediáticos. La puesta en marcha de servidores independientes, o el uso de sistemas y estándares abiertos y/o de software libre (Stallman, 2002), son los aliados tecnológicos preferentes de movimientos sociales de carácter emancipador. Se cuestionan con ello los modelos de propiedad intelectual mercantilistas, se proponen formas de trabajo colaborativo que redunden en el beneficio de la comunidad, y se reivindica el acceso libre y universal a determinados bienes, servicios y conocimientos (Sádaba, 2011).

\subsection{Comunicación multimodal y multicanal}

El diagnóstico común de que los mensajes transmitidos por los medios convencionales están sometidos a la fugacidad 
del momento, sin mayor análisis, seguimiento y profundidad, y que constituyen informaciones efímeras y demasiadas veces sesgadas por los grandes intereses corporativos, empujan a estos movimientos a llevar a cabo prácticas que cubran el déficit de independencia comunicativa propio de los medios tradicionales (Cardoso, 2008). Sin renunciar al impacto que son capaces de generar los medios convencionales, se plantea una apuesta paralela y creciente por desarrollar nuevos canales independientes, desligados del interés político y económico que subyace en los grandes medios de comunicación de masas, optando por una práctica comunicativa cada vez más multimodal y multicanal, heterogénea y diversa, acorde con los nuevos desafíos tecnológicos (Castells, 2007).

La "ética hacker" no sólo pretende dotar de medios y capacidades técnicas al incipiente activismo mediático, sino que lo dota de unos principios acordes a sus reivindicaciones

\subsection{Hacia una comunicación diacrónica plena}

En oposición al modelo informativo sincrónico propio de los medios de comunicación tradicional, ligado a un aquí y ahora en las emisiones y en la recepción, el uso de los nuevos medios por parte de movimientos y organizaciones sociales abre un horizonte informativo de plena diacronía donde los ciudadanos puedan obtener información continua no sometida a los arbitrios de las grandes corporaciones (Echeverría, 1999). En este camino hacia una comunicación diacrónica, la principal inquietud común ya no es luchar contra las injusticias del sistema, sino hacer comprender a los ciudadanos que forman parte de un sistema sociopolítico en el que las decisiones que se toman no las adoptan los políticos que aparentemente les gobiernan, sino los lobbies que gestionan los intereses corporativos a nivel transnacional. Los mensajes no están dirigidos ya de forma preferente a los militantes de las causas, sino al gran público, buscando involucrar a diferentes capas de la sociedad que puedan verse interpeladas por las injusticias que se denuncian.

\section{Notas}

1. Las cumbres del planeta, por poner un ejemplo, han sido objeto de un creciente interés por parte de los ciudadanos a partir de la información que se genera, provocada por la curiosidad de los impactos visuales de las organizaciones protestantes.

2. Es en este escenario en el que surge la idea de comunicación alternativa en los primeros años del auge de internet, que pretende establecer unas diferencias muy marcadas entre la comunicación convencional, aquella dependiente de grandes medios o conglomerados mediáticos, y la que pretendía abanderar un modelo de comunicación independiente.

3. En el caso de España, muchas de esas redes transnaciona- les fueron tomando cuerpo mediante acciones y campañas concretas como las del 0,7\% del PIB para desarrollo, o la de la abolición de la deuda externa de los países en desarrollo.

\section{Bibliografía}

Ayllón, Daniel (2015). "Nuevos proyectos periodísticos en red. El caso de La marea". Index.comunicación, v. 5, n. 2, pp. 53-60

http://journals.sfu.ca/indexcomunicacion/index.php/ indexcomunicacion/article/view/176/159

Baillie-Smith, Matt (2004). "Mediating the world: development, education and global citizenship". Globalisation, societies and education, v. 2, n. 1, pp. 1-24. http://www.tandfonline.com/toc/cgse20/2/1

Baillie-Smith, Matt (2013). "Public imaginaries of development and complex subjectivities: The challenge for development studies". Revue canadienne d'études du développement / Canadian journal of development studies, v. 34, n. 3, pp. 400-415.

https://goo.gl/bvpf8D

http://dx.doi.org/10.1080/02255189.2013.825204

Berardi, Franco (2007). Generación post-alfa: Patologías e imaginarios en el semiocapitalismo. Buenos aires: Tinta Limón. ISBN: 9789872314040

http://www.escritosdesocupados.com/descargas/ GENERACION-POST-ALFA-Franco-Berardo-Bifo.pdf

Candón, José (2011). Internet en movimiento: Nuevos movimientos sociales y nuevos medios en la sociedad de la información. Madrid: Universidad Complutense de Madrid. ISBN: 9788469420713

http://eprints.ucm.es/12085

Candón, José (2012). "Soberanía tecnológica en la era de las redes". Revista internacional de pensamiento político, v. 7, pp. 73-92

http://pensamientopolitico.org/Descargas/RIPP07073092. $p d f$

Cardoso, Gustavo (2008). Los medios de comunicación en la sociedad en red: filtros, escaparates y noticias. Barcelona: Editorial UOC. ISBN: 9788497888929

Casacuberta, David (2003). Creación colectiva: en internet el creador es el público. Barcelona: Editorial Gedisa. ISBN: 8474329280

Castells, Manuel (2006). La sociedad red: una visión global. Madrid: Alianza Editorial. ISBN: 9788420647845

Castells, Manuel (2007). "Communication, power and counter-power in the network society". International journal of communication, v. 1, n. 1, pp. 238-266.

http://ijoc.org/index.php/ijoc/article/viewFile/46/35

Castells, Manuel (2009). Comunicación y poder. Madrid: Alianza Editorial. ISBN: 9788420684994

Echeverría, Javier (1999). Los señores del aire: Telépolis y el tercer entorno. Barcelona: Destino. ISBN: 9788423331697

Enzensberger, Hans-Magnus (1970). “Baukasten zu einer Theorie der Medien”. Kursbuch, v. 20, pp. 159-186. 
Gillmor, Dan (2006). We the media: Grassroots journalism by the people, for the people. Sebastopol, CA: O'Reilly Media, Inc. ISBN: 9780596102272

Gutiérrez-Rubí, Antoni (2013). Tecnopolítica. Barcelona: Autopublicación. ISBN: 9788469717202

http://www.gutierrez-rubi.es/tecnopolitica

Haché, Alex (2015). Soberanía tecnológica. Barcelona: Autopublicación.

https://calafou.org/sites/calafou.org/files/libro_soberania_ tecnologica_cast_final.pdf

Himanen, Pekka (2001). La ética del hacker y el espíritu de la era de la información. Barcelona: Destino. ISBN: 978 0375505669

Jenkins, Henry (2004). "The cultural logic of media convergence". International journal of cultural studies, v. 7, n. 1, pp. 33-43.

http://dx.doi.org/10.1177/1367877904040603

Jenkins, Henry (2008). Convergence culture: Where old and new media collide. New York, London: NYU Press. ISBN: 978 0814742815

Juris, Jeffrey (2008). Networking futures: The movements against corporate globalization. Durham, NC: Duke University Press. ISBN: 9780822342694

Katz, James; Rice, Ronald (2002). Social consequences of internet use: Access, involvement, and interaction. Cambridge, MA: MIT press. ISBN: 9780262112697

Lessig, Lawrence (2004). Free culture: How big media uses technology and the law to lock down culture and control creativity. New York: Penguin Press. ISBN: 1594200068 http://www.free-culture.cc/freeculture.pdf

Lessig, Lawrence (2008). Remix: Making art and commerce thrive in the hybrid economy. New York: Penguin Press. ISBN: 9781408113479

López, Sara; Roig, Gustavo (2006). “Del tam-tam al doble click: Una historia conceptual de la contrainformación". En: Reunión de ovejas electrónicas. Ciberactivismo: Sobre usos políticos y sociales de la red. Barcelona: Virus, pp. 15-44. ISBN: 8496044726

López, Sara; Roig, Gustavo; Sádaba, Igor (2003). “Nuevas tecnologías y participación política en tiempos de globalización". Cuadernos de trabajo de Hegoa. Octubre, n. 35. Bilbao: Hegoa.

http://biblioteca.hegoa.ehu.es/system/ebooks/13176/ original/Cuaderno_de_trabajo_35.pdf

Lünenborg, Margreth; Raetzsch Christoph (2014). “Media practices and social change: Rethinking concepts of publics in the digital age". En: $5^{\text {th }}$ European Communication Conf. (Ecrea).
Manovich, Lev (1999). "What is digital cinema?". En: Lunenfeld, Peter. The digital dialectic: New essays on new media. Massachusetts: MIT Press, pp. 172-197. ISBN: 0262122138

Mazlish, Bruce; Sanz, Ángel-Luis; Arnáiz, Mercedes (1995). La cuarta discontinuidad: la coevolución de hombres y máquinas. Madrid: Alianza Editorial. ISBN: 8420628077

Nos, Eloísa; Iranzo, Amador; Farné, Alessandra (2012). “La eficacia cultural de la comunicación de las ONGD: los discursos de los movimientos sociales actuales como revisión". CIC Cuadernos de información y comunicación, n. 17, pp. 209237.

http://revistas.ucm.es/index.php/CIYC/article/view/39265

Nos, Eloísa; Pinazo, Daniel (2013). "Communication and engagement for social justice". Peace review, v. 25, n. 3, pp. 343-348.

http://repositori.uji.es/xmlui/bitstream/handle/10234/94350/ ID59710.pdf?sequence $=3$

http://dx.doi.org/10.1080/10402659.2013.816552

Pickerill, Jenny (2007). “'Autonomy online': Indymedia and practices and alter-globalisation". Environment and planning A, v. 39, n. 11, pp. 2668-2684.

http://dx.doi.org/10.1068/a38227

Sádaba, Igor (2011). Sociología de la propiedad intelectual en la era global. Madrid: Universidad Complutense de Madrid. ISBN: 9788466931465

Sampedro, Víctor (2014). El cuarto poder en red. Por un periodismo (de código) libre. Barcelona: Icaria. ISBN: 9788498885903

Singer, Jane; Domingo, David; Heinonen, Ari; Hermida, Alfred; Paulussen, Steve; Quandt, Thorsten; Reich, Zvi; Vujnovic, Marina (2011). Participatory journalism: Guarding open gates at online newspapers. New York: John Wiley \& Sons. ISBN: 9781444332278

Stallman, Richard (2002). Free software, free society: Selected essays of Richard M. Stallman. Boston, MA: Free Software Foundation. ISBN: 1882114981

Thorburn, David; Jenkins, Henry (2004). Rethinking media change: the aesthetics of transition. London: MIT Press. ISBN: 9780262701075

Tubella, Inma; Alberich-Pascual, Jordi (2012). Comprender los media en la sociedad de la información. Barcelona: Editorial UOC. ISBN: 9788497885584

Wolfson, Todd (2013). "Democracy or autonomy? Indymedia and the contradictions of global social movement networks". Global networks, 2013, v. 13, n. 3, pp. 410424.

http://onlinelibrary.wiley.com/doi/10.1111/glob.12030/pdf 